\title{
РОЛЬ ТОНКОМОЛОТОГО НАПОЛНИТЕЛЯ ТЕХНОГЕННОЙ ПРИРОДЫ В РЕЦЕПТУРЕ НАПОЛНЕННЫХ ВЯЖУЩИХ ДЛЯ ВЫСОКОКАЧЕСТВЕННЫХ БЕТОНОВ
}

\author{
Муртазаев C-A.Ю. ${ }^{1,2}$, \\ Саламанова М.Ш. ${ }^{1,2}$, \\ Сайдумов М.C. ${ }^{1}$, \\ Хубаев М.C-M. ${ }^{1}$ \\ ${ }^{1}$ ГГНТУ им. акад. М.Д. Миллионщикова, г. Грозный \\ ${ }^{2}$ КНИИ им. Х.И. Ибрагимова РАН, г. Грозный
}

В работе рассмотрено техногенное сырье различной природы на предмет получения из него тонкомолотого наполнителя для бетонных смесей, исследовано влияние минерального наполнителя техногенной природы на седиментационные показатели наполненных вяжущих и бетонных смесей на их основе.

Ключевые слова: техногенное сырье, бетонный лом, кирпичный бой, наполнитель, наполненное вяжущее, бетонная смесь, положительный эффект

В настоящее время в условиях внедрения массового высотного строительства на фоне возрастающих требований к материалам для их возведения современные бетоны стали многокомпонентными [1]. Так, современные высококачественные бетоны для высотного монолитного строительства состоят из 6-8 сырьевых компонентов, основными из которых являются вяжущее (как правило, наполненное или композиционные), мелкий и крупный заполнители, минеральные и химические добавки и вода. В ряде случаев могут применяться различные фибры, пигменты и другие добавки [2, 3].

Уже сегодня, как показывает строительная практика в нашей стране, все чаще применяют монолитные бетонные смеси, полученные с использованием так называемых наполненных вяжущих, которые по сути являются высокоактивными многокомпонентными вяжущими низкой водопотребности с нормальной густотой ниже $20 \%$.

Разработаны множество видов вяжущих с самыми разнообразными свойствами - от высокоактивных и быстротвердеющих до безусадочных и расширяющих. Наиболее распространенными среди них являются: вяжущие низкой водопотребности (BНB), тонкомолотый многокомпонентный цемент (ТМЦ), впервые исследованные и разработанные профессором Ю.М. Баженовым и его учениками $[4,5]$. Однако, требования к строительным материалам, отражающие действительность динамично развивающегося современного строительства, диктуют постоянные корректировки имеющих составов вяжущих, для чего требуется всесторонне исследовать роль тонкомолотых наполнителей таких вяжущих в процессе структурообразования. 
Так, в работе нами поставлена задача изучить влияние тонкомолотого наполнителя техногенной природы в рецептуре наполненных вяжущих для получения высококачественных бетонов с высокими показателями.

Из различных источников известно, что применение минеральных наполнителей (MH) различной природы совместно с пластифицирующими добавками в бетонных смесях приумножает эффективность использования последних. Так, в публикациях авторов [6, 7] отражены наполненные составы самоуплотняющихся смесей с применением микронаполнителя различной природы. Авторами работ [8, 9, 12, 13] констатировано положительное влияние тонкодисперсных частиц МН из утилизируемого строительного раствора на водоудерживающую способность, прочность, плотность и адгезию бетонных смесей.

Таким образом, предполагается, что минеральный наполнитель техногенного происхождения (МНТП) из бетонного лома и кирпичного боя, обладающих хорошей водоудерживающей способностью, будет больше всего подходить по своей структуре и природе происхождения для высокоподвижных бетонных смесей, способствующий в них своеобразному предотвращению седиментационных явлений.

В связи с этим нами изучена влияние тонкомолотого наполнителя техногенной природы на возможность стабилизации цементно-водных суспензий с его использованием, а именно:

- МНТП из бетонного лома;

- $\quad$ МНТП из керамического кирпичного боя (ККБ);

- МНТ из золошлаковых смесей (ЗШС);

- $\quad$ МН из мелких некондиционных кварцевых песков.

Удельная поверхность используемых нами МНТП находилась в диапазоне 450-600 м²/кг, что почти в 2 раза больше удельной поверхности цемента.

Полученные нами результаты сравнивались со специальными стабилизаторами из зарубежных продуктов - высоководоудерживающими добавками эфиров целлюлозы Bermocoll фирмы Akzonobel (Швеция), исследованными в работе $[10,11]$. Bermocoll - этил (оксиэтил) целлюлоза представляет собой неионогенный эфир целлюлозы.

Кинетика седиментации исследовалась на цементно-водных суспензиях, полученных на портландцементе M500 Д0 производства АО «Чеченцемент».

При значениях В/Ц = 1,6 оседание частиц дисперсной фазы в жидкости оканчивается в течение 0,4-1,0 часа, а сам процесс седиментации носит линейный характер. Повторное испытание с заменой «Чеченцемента» на «Новоросцемент» показало, что время седиментации и законы протекания данного процесса не зависят от вида цемента (рисунок 1). В полученных суспензиях МНТП дозировался от массы цемента в количестве 15 \%. 


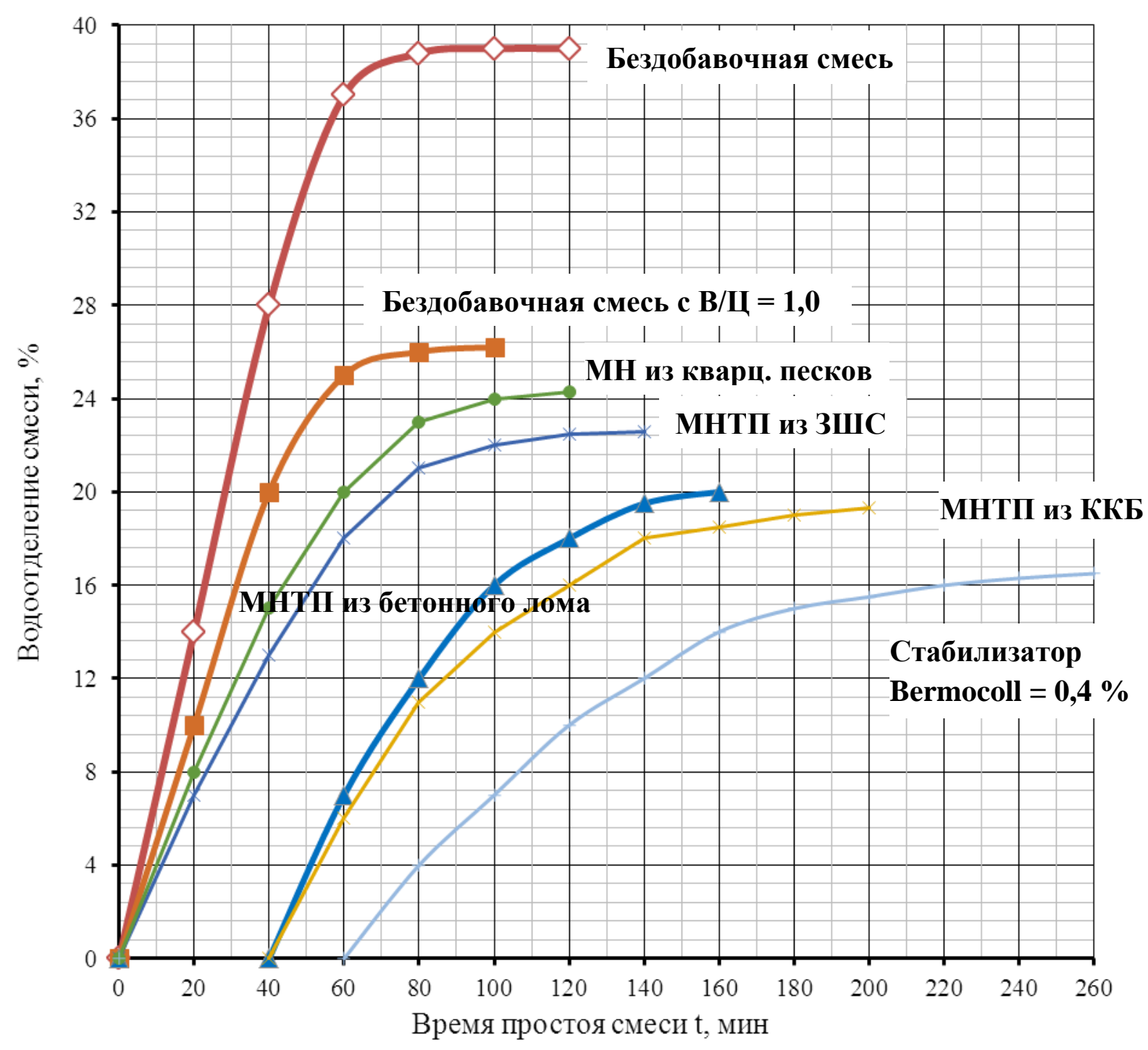

Рис. 1 - Кинетика седиментации цементных суспензий $(\mathrm{B} / Ц=1,6)$ с выделением осветленной воды над осадком смеси на цементе марки М500 Д0

Как видно из рисунка 1, количество осветленной воды над осадком бездобавочного цементного геля с В/Ц $=1,6$ находится в диапазоне от 36 до $39 \%$, а объем осадка при этом составляет 61-64\%.

Седиментация суспензий $\mathrm{c}$ В/Ц $=1,0$ протекает медленнее и заканчивается в течение 1,1-1,3 часов. Введение в состав цементно-водной суспензии МНТП заметно меняет ее седиментационные показатели в лучшую сторону. Так, результаты при использовании МНТП из бетонного лома и керамического кирпичного боя (ККБ) сопоставимы между собой и наиболее близки к значениям, полученным при использовании стабилизатора Bermocoll. Количество осветлённой воды над осадком в них не превышает 18-20\%. При этом начало водоотделения наблюдается после 40 минут. МНТП из золошлаковых смесей (ЗШС) и кварцевых песков заметно уступают по водоудерживающей способности МНТП из бетонного лома и ККБ. Это объясняется разной природой используемых МНТП (таблица 1). 
Таблица 1 - Водоудерживающая способность тонкомолотых наполнителей техногенного происхождения

\begin{tabular}{|l|l|l|l|l|}
\hline $\begin{array}{l}\text { № } \\
\text { п.п. }\end{array}$ & Вид наполнителя & $\begin{array}{l}\text { Сырье, из которого } \\
\text { получен наполнитель }\end{array}$ & $\begin{array}{l}\text { Количество связанной } \\
\text { воды (после } \\
\text { центрифугирования, г/г }\end{array}$ & $\begin{array}{l}\text { Удельная } \\
\text { поверхность } \\
\text { Sуд, мкг }\end{array}$ \\
\hline 1 & $\begin{array}{l}\text { МНТП из } \\
\text { бетонного лома }\end{array}$ & Бетонный лом & 0,1803 & $560-580$ \\
\hline 2 & То же, из ККБ & $\begin{array}{l}\text { Керамический } \\
\text { кирпичный бой }\end{array}$ & 0,2112 & $580-600$ \\
\hline 3 & То же, из ЗШС & $\begin{array}{l}\text { Золошлаковые смеси } \\
\text { ТЭЦ }\end{array}$ & 0,7020 & $550-570$ \\
\hline 4 & $\begin{array}{l}\text { МН из кварц. } \\
\text { песков }\end{array}$ & $\begin{array}{l}\text { Некондиционные } \\
\text { кварцевые пески }\end{array}$ & 0,1688 & $460-480$ \\
\hline
\end{tabular}

В работе при проведении исследований использовался метод центрифугирования, при котором образцы тонкодисперсных частиц МНТП выдерживались в стеклянных колбах диаметром 15 мм, плотно закрытых с одной стороны фильтровальной бумагой.

Следовательно, из всех исследуемых добавок (за исключением дорогостоящего специального стабилизатора Bermocoll) наиболее существенно стабилизирует цементные суспензии МНТП из бетонного лома и ККБ. Эти добавки снижают эффект седиментации частиц даже при сильном разбавлении суспензий жидкой фазой (с В/Ц $=1,6)$. А применение МНТП совместно с пластифицирующими добавками, в разы, снижающие В/Ц, в комплексе даст еще больший эффект по предотвращению седиментации бетонных смесей.

Стабилизирующая функция МНТП оценивалась нами на бетонных смесях с использованием тяжелых плотных природных гранитно-диабазовых заполнителей плотностью более 2,6 г/ $\mathrm{cm}^{3}$. Расход составляющих компонентов бетонной смеси для контрольного состава был принят следующим: цемент местный - 520 кг, песок Червленский - 600 кг, щебень - 1200 кг, при В/Ц = 0,39. Экспериментальные составы с применением МНТП и химических добавок проектировались относительно контрольного.

Пластификация бетонных смесей производилась химической добавкой «Линамикс ПК», расход которой составлял около 1,1 \% от массы цемента. МНТП дозировались от массы цемента в количестве $15 \%$ каждый. Из полученных смесей формировались цилиндры диаметром 100 мм и высотой 1000 мм в вертикальном положении в специально изготовленных металлических формах, состоящих из двух частей - полуформ. Для усиления расслаиваемости смеси были запроектированы с маркой по осадке конуса П5 (ОК более 20 см) и уплотнялись на виброплощадке в течении 0,5 мин. Следы седиментации твердых частиц в структуре бетона исследовали по разнице в верхних и нижних слоях изготовленных образцов. Для этого на вспомогательном оборудовании по резке бетонных образцов были выпилены цилиндры диаметром и высотой 100 мм, на которых определялась плотность и прочность бетона в верхних и нижних слоях образца (таблица 2). 
Анализ таблицы 2 показывает, что разница в плотности контрольного бездобавочного бетона по высоте достигает до 200 кг $/ \mathrm{m}^{3}$, что составляет 8-12\%. Использование в бетонных смесях МНТП позволяет уменьшить разницу в плотности до 72 кг/м ${ }^{3}$ (т.е. около $3 \%$ от плотности бетона), и в прочности - до 4 МПа. При этом поверхность в верхней части образца в сравнении с контрольным составом бетона не имела рыхлого и слабого поверхностного слоя. Химическая добавка «Линамикс ПК» в количестве $1,1 \%$ также оказалась достаточно эффективной. При ее введении в бетонную смесь совместно с МНТП разница в плотности уменьшилась до 43 кг $/ \mathrm{M}^{3}$ (это менее $2 \%$ от плотности бетона), а в прочности - до 1,5-2,0 МПа.

Таблица 2 - Градиенты плотности бетона при расслоении тяжелых бетонных смесей

\begin{tabular}{|c|c|c|c|c|c|c|c|c|}
\hline \multirow{2}{*}{$\begin{array}{l}\text { E } \\
\text { 日 } \\
\text { ol } \\
2\end{array}$} & \multicolumn{2}{|c|}{ Добавка } & \multicolumn{2}{|c|}{ Плотность, кг/м³ } & \multirow{2}{*}{ 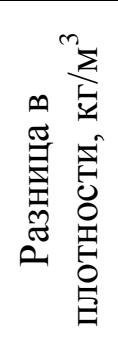 } & \multicolumn{2}{|c|}{$\begin{array}{c}\text { Прочность } \mathrm{R}_{\mathrm{C}}{ }^{28} \\
\text { МПа }\end{array}$} & \multirow{2}{*}{ 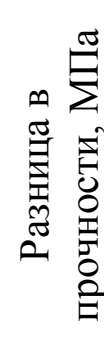 } \\
\hline & минеральная & химическая & $\begin{array}{c}\text { нижний } \\
\text { слой }\end{array}$ & $\begin{array}{c}\text { верхний } \\
\text { слой }\end{array}$ & & $\begin{array}{c}\text { нижний } \\
\text { слой }\end{array}$ & $\begin{array}{c}\text { верхний } \\
\text { слой }\end{array}$ & \\
\hline 1 & - & - & 2558 & 2360 & 198 & 47,8 & 40,3 & 7,5 \\
\hline 2 & $\begin{array}{c}\text { МНТП из } \\
\text { бетонного лома }\end{array}$ & - & 2470 & 2398 & 72 & 46,9 & 42,8 & 4,1 \\
\hline 3 & То же & $\begin{array}{c}\text { Линамикс } \\
\text { ПК }\end{array}$ & 2468 & 2425 & 43 & 49,9 & 48,0 & 1,9 \\
\hline 4 & МНТП из ККБ & - & 2466 & 2390 & 76 & 44,9 & 41,0 & 3,9 \\
\hline 5 & То же & $\begin{array}{l}\text { Линамикс } \\
\text { ПК }\end{array}$ & 2450 & 2407 & 43 & 48,8 & 47,3 & 1,5 \\
\hline 6 & МНТП из ЗШС & - & 2491 & 2399 & 92 & 48,7 & 44,5 & 4,2 \\
\hline 7 & То же & $\begin{array}{c}\text { Линамикс } \\
\text { ПК } \\
\end{array}$ & 2485 & 2423 & 62 & 50,2 & 47,9 & 2,3 \\
\hline 8 & $\begin{array}{c}\text { МН из } \\
\text { кварцевых } \\
\text { песков }\end{array}$ & - & 2498 & 2390 & 108 & 48,9 & 45,0 & 3,9 \\
\hline 9 & То же & $\begin{array}{c}\text { Линамикс } \\
\text { ПК }\end{array}$ & 2489 & 2435 & 54 & 51,3 & 46,8 & 4,5 \\
\hline
\end{tabular}

На основании сравнительных результатов исследования эффективности тонкомолотых минеральных наполнителей техногенной природы (МНТП) в качестве наполнителя для получения наполненных вяжущих нами использован два вида наполнителя: МНТП из бетонного лома и ККБ в соотношении 70:30 \% (таблица 3). 
Таблица 3 - Рецептура наполненных вяжущих (НB) с тонкомолотым минеральным наполнителем техногенной природы (МНТП)

\begin{tabular}{|c|c|c|c|c|}
\hline \multirow{3}{*}{ Вид вяжущего } & \multicolumn{4}{|c|}{ Состав НB, \% по массе } \\
\hline & \multirow{2}{*}{$\begin{array}{l}\text { ПЦ М500 Д0 } \\
\text { «Чеченцемент» }\end{array}$} & \multicolumn{2}{|c|}{ МНТП } & \multirow{2}{*}{$\begin{array}{l}\text { Добавка } \\
\text { Д-5 }\end{array}$} \\
\hline & & из бетонного лома & из ККБ & \\
\hline $\begin{array}{l}\text { Наполненное вяжущее } \\
\text { марки НB-75:25 }\end{array}$ & 75 & 16 & 7 & 2 \\
\hline То же, HB-60:40 & 60 & 27 & 11 & 2 \\
\hline
\end{tabular}

Объем и характер пор цементного камня, образованного из портландцемента и полученных составов НB, во многом определяющие физико-механические показатели цементных композиций, включая его прочность, морозо- и коррозионная стойкость, проницаемость и др., исследовались нами методом ртутной порометрии. Анализ данных показало, что пористость цементного камня, образованного из обычного портландцемента, резко отличается от цементного камня на основе НВ. Так, в 2 раза снижается количество пор с диаметром более 2,0 мкм, в 4 раза уменьшается содержание капиллярных пор диаметром 2,0-0,2 мкм, происходит сдвиг эффективного диметра пор в сторону тонких капилляров. Это хорошо видно на кривых распределения пор по размерам в цементном камне в зависимости от вида используемого вяжущего (рисунок 2).

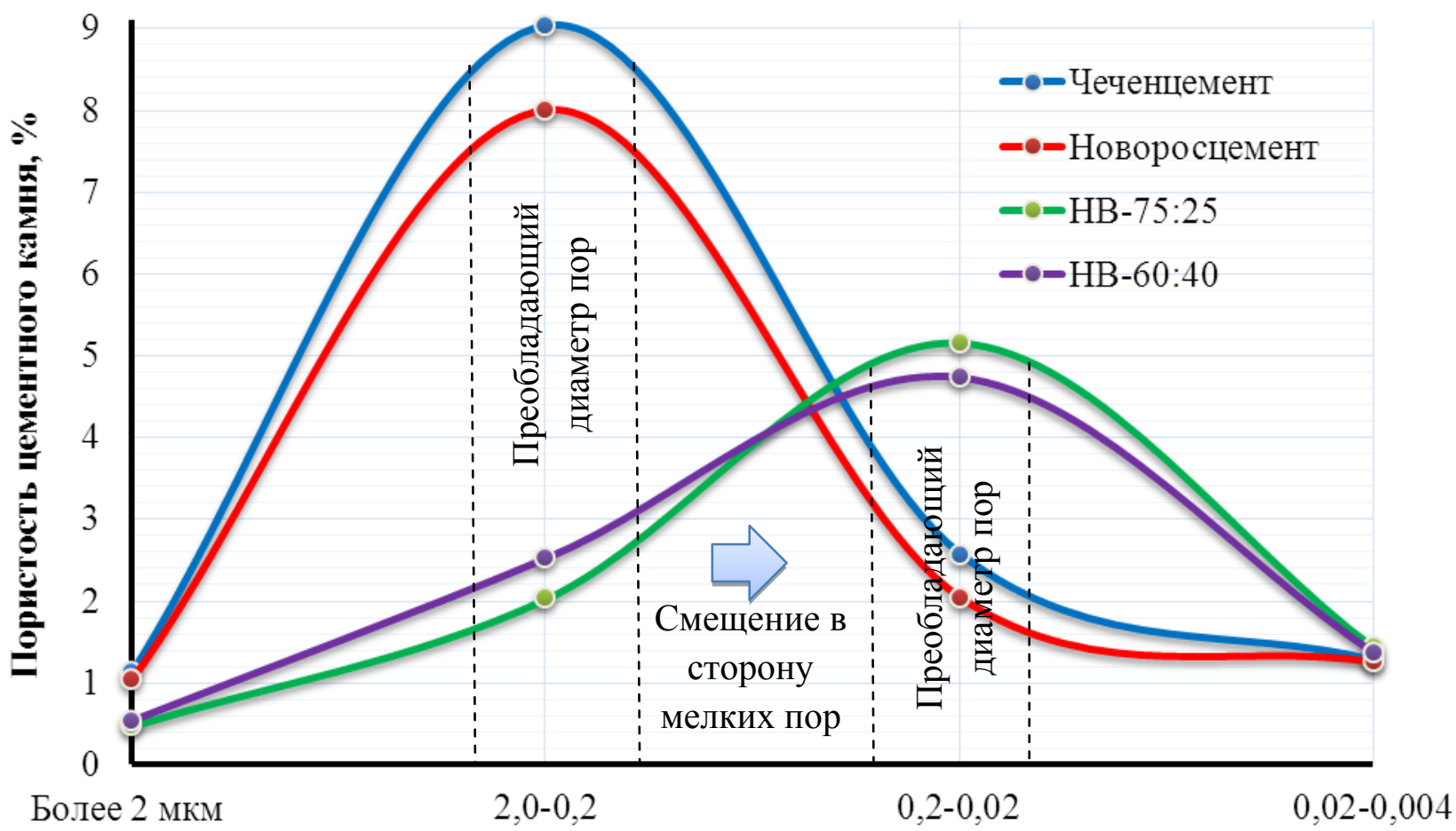

Распределение пор по размерам, мкм

Рис. 2 - Кривые распределения пор по размерам в цементном камне в зависимости от вида вяжущего 
Также установлено, суммарная пористость бетона на НВ практически в 1,4-1,6 раза меньше микропористости цементного камня на обычном портландцементе, что свидетельствует о положительном влиянии тонкомолотых наполнителей в составе наполненных вяжущих на основные их свойства.

Таким образом, на основании исследований влияния тонкомолотых наполнителей техногенной природы на реологию, в целом, и на седиментационные показатели, в частности, установлено, что для обеспечения требуемой стабилизации структурных характеристик от расслоения рекомендуется введение тонких наполнителей в бетонные смеси, а для получения более плотной структуры цементного камня - использовать их совместно с химическими добавками-водопонизителями, что обеспечивает более весомый комплексный и технологический и экономический эффект.

\section{Исследование выполнено при финансовой поддержке РФФИ в рамках научного проекта № 18-48-200001.}

\section{Список литературы}

1. Баженов, Ю.М. Обзор современных высокоэффективных бетонов / Ю.М. Баженов, Р.С. Федюк, В.С. Лесовик // Наукоемкие технологии и инновации. Электронный сборник докладов Международной научно-практической конференции, посвященной 65-летию БГТУ им. В.Г. Шухова. 2019. - С. 45-49.

2. Alekseev, V.A. Modified binder for sprayed concrete / V.A. Alekseev, Yu.M. Bazhenov, S.I. Bazhenova, O.Yu. Bazhenova, N.A. Golovashchenko, N.S. Mironchuk // БСТ: Бюллетень строительной техники. 2018. -№ 5 (1005). -С. 18 19.

3. Murtazaev, S.-A. High-quality concretes for foundations of the multifunctional high-rise complex(MHC) "Akhmat Tower" / Murtazaev S.-A., Saydumov M., Alaskhanov A., Nakhaev M. // B сборнике: 14th International Congress for Applied Mineralogy (ICAM2019) Cep. "Springer Proceedings in Earthand Environmental Sciences" 2019. -C. 365-368.

4. Каприелов, С.С. Цементы и добавки для производства высокопрочных бетонов / С.С. Каприелов, А.В. Шейнфельд, В.Г. Дондуков // Строительные материалы. 2017. -№ 11. -С. 4-10.

5. Аласханов, А.Х. Разработка составов наполненных вяжущих на основе вторичного сырья для монолитных высокопрочных бетонов / А.Х. Аласханов, Т.С.А. Муртазаева, Омаров А.О. [и др.] // Вестник Дагестанского государственного технического университета. Технические науки. 2019. -Т. 46. -№ 3. -C. 129-138.

6. Несветаев, Г.В. Самоуплотняющиеся бетоны: прочность и проектирование состава [Текст] / Г.В. Несветаев, А.Н. Давидюк // Строительные материалы. -2009. -№ 5. -С.54-57. 
7. Кудяков, А.М. Влияние зернового состава и вида наполнителей на свойства строительных растворов [Текст] /А.М. Кудяков, Л.А. Аниканова, Н.О. Копаница // Строительные материалы. - 2001. - № 11. - С.28-29.

8. Усов, Б.А. Сухие строительные смеси на основе молотого портландцемента к кварцосодержащими микронаполнителями [Текст] / Б.А. Усов, Л.Н. Попов // Строительные материалы, оборудование, технологии XXI века. - 2003. - №7. - С.14-15.

9. Шангина, Н.Н. Адсорбционно-каталитические процессы на поверхности твердой фазы и их влияние на свойства бетонов [Текст] /Н.Н. Шангина, А.П. Лейкин // Молодые ученые, аспиранты и докторанты. Петербургский гос. ун-та путей сообщения. - СПб. - 1997. - С.28-34.

10. Баженов, Ю.М. Модифицированные высококачественные бетоны [Текст]: научное издание / Ю.М. Баженов, В.С. Демьянова, В.И Калашников. М.: Издательство Ассоциации строительных вузов, 2006. - 368 с.

11. Ахвердов, И.Н. Теоретические основы бетоноведения [Текст] / И.Н. Ахвердов. - Минск: Высшая школа, 1991. -188 с.

12. Murtazaev, S.-A.Yu. Building demolition products as a secondary raw material for high-strength concrete / S.-A.Yu. Murtazaev, M.S. Saidumov, A.Kh. Alaskhanov [и др.] // В сборнике: Atlantis Highlights in Material Sciences and Technology Proceedings of the International Symposium "Engineering and Earth Sciences: Applied and Fundamental Research" dedicated to the 85th anniversary of H.I. Ibragimov (ISEES 2019). 2019. -C. 476-480.

13. Lesovik, V. Geonics (geomimetics) as a theoretical basis for new generation compositing / V. Lesovik, A. Volodchenko, E. Glagolev, I. Lashina, H.B. Fischer // B сборнике: 14th International Congress for Applied Mineralogy (ICAM2019) Cep. "Springer Proceedings in Earthand Environmental Sciences" 2019. -C. 344-347. 